\title{
A taxonomical study of benthic Prorocentrum species (Prorocentrales, Dinophyceae) from Anse Dufour (Martinique Island, eastern Caribbean Sea)
}

\author{
Chomérat Nicolas ${ }^{1,}{ }^{*}$, Bilien Gwenaël ${ }^{1}$, Zentz Frédéric ${ }^{2}$
}

\author{
1 IFREMER, ODE/LER Bretagne Occidentale, Station de Biologie Marine, Place de la Croix, F-29900 \\ Concarneau, France. \\ 2 Université de Bretagne Occidentale, Station de Biologie Marine, Place de la Croix, F-29900 \\ Concarneau, France \\ *Corresponding author : Nicolas Chomérat, email address : nicolas.chomerat@ifremer.fr
}

\begin{abstract}
:
About 30 benthic Prorocentrum species have been described, some of which producing okadaic acid and derivatives involved in diarrhetic shellfish poisoning. The western Caribbean has been extensively studied for benthic dinoflagellates associated with ciguatera, and fifteen Prorocentrum species were described from mangroves and coral reefs of Belize. In contrast, no study reported the diversity of this genus in the Eastern Caribbean, especially in the Lesser Antilles. This study adds to the biodiversity knowledge in Martinique Island by investigating one site of the Caribbean coast from 2010 to 2017. Sediment samples were collected each year in March and studied taxonomically. Identification was realized morphologically by scanning electron microscopy, while the partial large subunit (LSU) ribosomal DNA was sequenced for 42 isolated specimens (single-cells) and one strain in culture. A molecular phylogenetic analysis revealed 11 OTUs from Martinique, identified morphologically as $P$. concavum, $P$. cf. foraminosum, $P$. cf. tropicale, $P$. lima, $P$. hoffmannianum, $P$. cf. norrisianum, $P$. glenanicum, $P$. panamense, $P$. cf. sculptile, $P$. cf. fukuyoi, and $P$. rhathymum. Two morphospecies were also identified ( $P$. cf. maculosum and $P$. cf. ruetzlerianum) but with no sequence obtained. Some species like $P$. cf. tropicale and $P$. cf. norrisinamum are sequenced for the first time. Our analysis reveals probable former misidentifications of $P$. cf. foraminosum and $P$. cf. sculptile since the sequences from Martinique form new clades and their geographical origin are closer from the type locality than any other previous studies. Further studies and sequences from the type localities are yet required to assess identifications.
\end{abstract}

Keywords : Caribbean, Dinoflagellates, LSU rDNA, Phylogeny, Prorocentrum, Taxonomy 
Introduction

37 The Caribbean area has been long investigated for potentially toxic microalgae responsible of ciguatera. In the 90s, M.A. Faust published a remarkable series of papers on the biodiversity of benthic dinoflagellates from tropical ecosystems of Belize (Faust 1990a; b, 1991, 1993a; b, 1994, 1997, 2009; Faust et al. 2008). In addition to her investigations of the toxigenic genera Gambierdiscus and Ostreopsis (Faust 1995, 1999; Faust and Morton 1995), she made a major contribution to the genus Prorocentrum for which she described fifteen benthic Prorocentrum morphospecies from mangrove habitats of Twin Cays and lagoonal waters at Carrie Bow Bay. To date, some of these species like $P$. ruetzlerianum Faust, $P$. sabulosum Faust or $P$. tropicale Faust are still poorly known, since they have not been reported in any other location than their type locality.

Although the morphology of Prorocentrum can be considered as simple owing to the presence of only two main lateral plates and several small platelets in the periflagellar area, the species delimitation in this genus is complex (Hoppenrath et al. 2013). Some morphological characters are now recognized as valuable taxonomic features, such as the number and organization of periflagellar platelets, but they have not been characterized with enough accuracy in several original descriptions (Hoppenrath et al. 2013). In contrast, such features as the size, shape and the ornamentation are variable and not reliable enough for species identification. To date, about 71 species have been described and have been flagged as accepted (Guiry and Guiry 2018), of which half are benthic or epiphytic. More species have been described on a morphological basis, but the use of molecular taxonomy and sequencing of ribosomal DNA genes or internal transcribed spacers ITS1 and ITS2 showed that some closely related morphotypes possessed very similar genotypes and synonymies have been proposed. For instance $P$. arabianum Morton \& Faust is now regarded as a junior synonym of $P$. concavum Fukuyo (Mohammad-Noor et al. 2007b). More recently, an extensive study revealed that $P$. belizeanum Faust can be regarded as conspecific with $P$. hoffmannianum Faust (Herrera-Sepúlveda et al. 2015). Nevertheless, some synonymies like P. arenarium Faust which has been proposed as a synonym of $P$. lima (Nagahama et al. 2011) are not commonly accepted by all authors. The level of morphological and genetic variability is very high in ' $P$. lima' and the species delimitation is not clear, leading to consider this taxon as a species complex (Bouaïcha et al. 2001; Nagahama et al. 2011; Hoppenrath et al. 2013). Some authors have recognized different morphotypes associated with some genetic variability but did not propose them as separate species (Zhang et al. 2015). Only recently, $P$. 
caipirignum Fraga, Menezes \& Nascimento has been described as a separate species in this complex

67 (Nascimento et al. 2017), on the basis of a molecular analysis of the ITS region since no support was found with LSU rDNA. In this study, the authors suggested that $P$. arenarium could be considered as separate species, while the circumscription of $P$. lima should be reevaluated. Another case of a problematic species complex with a considerable genetic variation among specimens and populations is the group $P$. emarginatum/P. fukuyoi. These two species share several morphological characters such as the asymmetry, the thecal pore pattern and a peculiar periflagellar area with a wing on platelet 1. Specimens with this peculiar morphology have been found in various places around the world, but due to their resemblance, their identification was unclear (e.g. Faust 1990a; Mohammad-Noor et al. 2007a; Laza-Martínez et al. 2011), which generated many confusions and misinterpretations (Hoppenrath et al. 2013). Even when molecular data was available, the considerable genetic variability observed in this complex did not allow to conclude on the identity of the specimens (e.g. LazaMartínez et al. 2011; Hoppenrath et al. 2013). This level of genetic divergence may indicate the existence of cryptic or pseudocryptic species in this complex, but in order to clarify their boundaries, further molecular analyses from various locations in the world are absolutely necessary.

In contrast with the western part of the Caribbean, taxonomic studies focusing on the diversity of benthic dinoflagellates are scarce in French Antilles (also known as French West Indies). In a previous study, Chomérat and Bilien (2014) described Madanidinium loirii Chomérat, a new dinoflagellate from Martinique Island. A few other surveys focused on the toxigenic genera Gambierdiscus and Ostreopsis associated with ciguatera (Besada et al. 1982; Taylor 1985; Litaker et al. 2010; Boisnoir et al. 2018) since intoxications have been recurrently documented in this area (Olsen et al. 1984; Vernoux 1988; Pottier et al. 2001; Rosine et al. 2008; Tester et al. 2010). Although it has been shown that several benthic Prorocentrum species produce toxins such as okadaic acid, dinophysistoxins and fast acting toxins (Faust et al. 1999; Faust and Gulledge 2002; Lassus et al. 2016; Luo et al. 2017), no taxonomic study on this genus has been realized in this area. The aim of the present study is to investigate the diversity of benthic Prorocentrum species in one site of Martinique Island using a observations of the morphology by microscopy, and sequencing the partial large subunit of ribosomal DNA (LSU rDNA) from single cells. This data will be used in a phylogenetic analysis in order to perform genetic comparisons and better understand the level of genetic variability within species. Furthermore, this analysis will be helpful to better appreciate the biogeography of some 
96 species and to bring new insights on the evolution of the Prorocentrales, which is a very distinctive

97 group among dinoflagellates.

98

\section{Material and methods}

\section{Sampling and culturing}

101 Surface sediment (“organic dust”) samples have been collected recurrently each Spring (in March)

102 from 2010 onwards (2010-2017) at one sampling site located in the Anse Dufour (coordinates

$\left.1031^{\circ} 31.538^{\prime} \mathrm{N} ; 6^{\circ} 5.446^{\prime} \mathrm{W}\right)$, on the Caribbean coast of the Island (Chomérat and Bilien 2014). Five

104 samples collected the 16 March 2010, 20 and 27 March 2012, 27 March 2015, and 30 March 2017

105 were used in the study. Immediately after being collected in snorkelling, the samples were fixed with

106 acidic Lugol's solution, while one subsample from 2017 was kept fresh and transported to the

107 Concarneau laboratory alive in less than 48h. In the laboratory, Lugol-fixed samples were stored at 4

$108{ }^{\circ} \mathrm{C}$ in the dark, while the fresh sample was used for isolation of interesting species in order to establish

109 cultures. For cultivation, single cells from the live sediment sample were isolated and processed as

110 described in Chomérat and Bilien (2014). One strain was successfully established (IFR-PTR-01M)

111 and grown in K/5 medium (Keller et al. 1987) in an incubator set up at $22 \pm 1.0{ }^{\circ} \mathrm{C}$ and a 12:12

112 light:dark illumination cycle with $\sim 50 \mu \mathrm{mol}$ photons $\mathrm{m}^{-2} \mathrm{~s}^{-1}$ provided by white fluorescent tubes.

\section{Scanning electron microscopy}

115 For scanning electron microscopy, cells were first individually isolated and concentrated in $2 \mathrm{ml}$ tubes

116 containing water and a drop of formaldehyde to prevent development of fungi in the water. Then, cells

117 were filtered on polycarbonate membrane filters (Millipore RTTP Isopore, $1.2 \mu \mathrm{m}$ pore size,

118 Millipore, Billerica, USA), rinsed in deionised water and prepared according to Chomérat and Couté

119 (2008). After gold-coating, SEM examinations were carried out with a Quanta 200 (FEI, Eindhoven,

120 The Netherlands) scanning electron. Cells were measured on SEM digital micrographs using ImageJ

121 software (Rasband 1997). SEM images were presented on a uniform background using GNU Image 
122 Manipulation Program v.2.8.22. The terminology used for thecal plates and periflagellar platelets in

123 this paper follows the system of Hoppenrath et al. (2013).

\section{DNA amplification and molecular analyses}

126 For single-cell isolation, the tube containing Lugol fixed sample was vigorously shaken and a subsample of $30 \mu \mathrm{l}$ was diluted in $4 \mathrm{ml}$ of filtered seawater in a small Petri dish. A Olympus IX51 (Olympus, Tokyo, Japan) inverted microscope was used to search the cells of interest. They were isolated with a micropipette under the inverted microscope and rinsed in four drops of distilled water before being transferred into a $200 \mu \mathrm{l}$ PCR tube. Each cell was measured and pictured using a Olympus E-300 digital camera to register the morphological features used for identification. In some cases, when the identification was not possible with LM only, cells were dissected under the inverted microscope using the pipette. Large lateral plates were observed, photographed, and then transferred onto a SEM-stub bearing a poly-L-lysine coverslip with an engraved grid in order to examine them by SEM. The cell protoplast was rinsed and placed in a PCR tube containing $5 \mu$ of ultrapure water. This process allowed us to associate the precise morphology of the theca of a specimen with its sequence. Tubes containing single cells were stored at $-20^{\circ} \mathrm{C}$ until further analysis. For PCR, tubes were thawed and processed as described in Chomérat et al. (2012).

All sequences obtained in this study have been deposited in GenBank and accessory numbers 140 are given in Fig. 1.

\section{Phylogenetic analysis}

143 For the phylogenetic analysis, 43 sequences acquired from single cells of Prorocentrum were aligned 144 together with 90 LSU sequences of other Prorocentrum species and 2 sequences of Peridiniella (as 145 outgroup) retrieved from GenBank. The sequences were aligned using MAFFT software version 7 146 with selection of the Q-INS-i algorithm which considers the secondary structure for the alignment 147 (Katoh and Standley 2013). This step was followed by refinement by eye with MEGA software version 148 5.2.1 (Tamura et al. 2011). The final data matrix contained 135 LSU rDNA sequences and 643 sites. 149 The best-fitting model of substitution, according to the Akaike Information Criterion (AIC), the Bayesian Information Criterion (BIC) and hierarchical Likelihood-ratio tests (hLRTs), was selected 
using ModelGenerator v. 0.82 (Keane et al. 2006). General time reversible (GTR) model with a

152 gamma correction $(\Gamma)$ for among-site rate variation and invariant sites was chosen from one of the best

153 models for the LSU dataset. The parameters of the model were as follows: Log-likelihood:-

154 8260.79059; Unconstrained likelihood: -3627.54489; Parsimony: 1701; Tree size: 4.35007; Discrete

155 gamma model; Number of categories: 8; Gamma shape parameter: 0.971; Proportion of invariant:

156 0.086; Nucleotides frequencies: $\mathrm{f}(\mathrm{A})=0.22706, \mathrm{f}(\mathrm{C})=0.21750, \mathrm{f}(\mathrm{G})=0.31135, \mathrm{f}(\mathrm{T})=0.24409$; GTR

157 relative rate parameters: $\mathrm{A} \leftrightarrow \mathrm{C}: 1.07364, \mathrm{~A} \leftrightarrow \mathrm{G}: 3.15646, \mathrm{~A} \leftrightarrow \mathrm{T}: 1.02071, \mathrm{C} \leftrightarrow \mathrm{G}: 0.61559, \mathrm{C} \leftrightarrow \mathrm{T}:$

1587.74009 and $\mathrm{G} \leftrightarrow \mathrm{T}: 1.00000$. The evolutionary models were examined using maximum likelihood

159 (ML) and Bayesian Inference analysis (BI). Maximum likelihood analyses were performed using

160 PhyML version 3.0 (Guindon et al. 2010), and Bayesian analyses were run using Mr Bayes version

1613.1 .2 (Ronquist and Huelsenbeck 2003). Bootstrap analysis (1000 pseudoreplicates) was used to

162 assess the relative robustness of branches of the ML tree. Initial Bayesian analyses were run with a

163 GTR model (nst = 6) with rates set to invgamma (gamma for LSU dataset). Each analysis was

164 performed using four Markov chains (MCMC), with two millions cycles for each chain. Trees were

165 saved every 100 cycles and the first 2000 trees were discarded. Therefore, a majority-rule consensus

166 tree was created from the remaining 18,000 trees in order to examine the posterior probabilities of

167 each clade.

168

169 Genetic distances were calculated on the same alignment using Kimura 2-parameter (Kimura 1980)

170 model in MEGA 5 software.

171

172 Results and discussion

173 In order to present the taxa in an order reflecting their phylogenetic relationships, this section is

174 presented with the molecular analysis first, allowing to define major clades. In each clade, the

175 morphological features of the species identified in the study are described and discussed. 


\section{Phylogenetic analysis}

178 The molecular phylogeny inferred from LSU rDNA revealed that the 43 sequences acquired in this

179 study clustered in six major clades (Fig. 1). The clade A comprises sequences identified as $P$. concavum and related species. It forms a sister clade (with a moderate support) to the clade B which encompasses the species related to $P$. lima forming the 'P. lima complex'. At the base of these two clades, the clade $\mathrm{C}$ groups sequences of $P$. borbonicum and $P$. sipadanense for which no sequence have been obtained in the present study. In contrast, the clade D comprises only new sequences acquired in this study and identified as $P$. cf. norrisianum. The clade E encompasses sequences of $P$. panamense and $P$. glenanicum. The clade F groups the sequences attributed to species from the $P$. emarginatum/fukuyoi complex and exhibits a high level of genetic variation, with several subclades. The clade $\mathrm{G}$ comprises the epibenthic species $P$. rhathymum but also planktonic species of Prorocentrum.

\section{Clade A - Prorocentrum concavum and related species}

191 Nine sequences from Martinique Island clustered in this clade. Two sequences grouped with other sequences of $P$. concavum retrieved from GenBank (subclade A1), while the other sequences form new branches and did not group with any sequence. The sequence of the strain IFR-PTR-01M $(P$. cf. tropicale) branched at the base of the clade A and the remaining 6 almost identical sequences

195 (subclade A3) formed a sister-clade to $P$. leve with a good support, and were ascribed to $P$. cf.

196 foraminosum on a morphological basis.

197 - Prorocentrum concavum Fukuyo (subclade A1)

198 Syn. P. faustiae Morton

199 Cells were broadly oval in shape (Figs $2 \mathrm{~d}-\mathrm{e}$ ), $46-48 \mu \mathrm{m}$ in length (mean $45.8 \mu \mathrm{m}$, s.d. $1.8 \mu \mathrm{m}, \mathrm{n}=4$ )

200 and 38-44 $\mu \mathrm{m}$ in width (mean $40.0 \mu \mathrm{m}$, s.d. $3.1 \mu \mathrm{m}, \mathrm{n}=4$ ). The length to width ratio varied from

2011.06 to 1.24. The periflagellar area was V-shaped, composed of 9 platelets (1a, 1b, 2, 3, 4, 5, 6, 7 and

202 8), but platelet '7' was not clearly visible and hidden by platelet 1 (Fig. 2f). The apical part of the left 203 lateral plate was granular (Fig. 2e). The thecal surface was reticulate-foveate (Figs 2d-f) with 
204 scattered thecal pores, except in the centre of lateral plates. Thecal pores were $0.25-0.30 \mu \mathrm{m}$ in 205 diameter.

The original size range given by Fukuyo (1981) was $44-45 \mu \mathrm{m}$ in length and $40 \mu \mathrm{m}$ in width 208 but Faust (1990a) reported larger cells. Morton (1998) gave a size range only slightly wider for $P$. 209 faustiae from reef flats of Heron Island (Great Barrier Reef), 43-49 $\mu \mathrm{m}$ in length and 38-42 in width, 210 while Mohammad Noor (2007a) reported a similar range (43-53 $\mu \mathrm{m}$ in length and 38-48 $\mu \mathrm{m}$ in 211 width) for $P$. concavum but a larger range (45-60 $\mu \mathrm{m}$ in length and 38-53 $\mu \mathrm{m}$ in width) for specimens 212 identified as $P$. faustiae. More recently, a Chinese study reported cells of $P$. concavum being 45.7$21350.2 \mu \mathrm{m}$ long and 37.7-42.4 $\mu \mathrm{m}$ wide (Luo et al. 2017), which is very close to our observations. In the 214 phylogenetic analysis (Fig. 1), all sequences clustered in a well resolved clade with a very low level of 215 genetic variation (mean genetic distance 0.008). Although one of these sequences from Malaysia was 216 ascribed to $P$. faustiae (EF566744), its distance with other sequences in the clade varies from 0.002 to 217 0.012, which is low. The topology suggests the existence of only one monophyletic species, with slight 218 intraspecific variation as found for specimens from Martinique Island. Therefore, as discussed earlier 219 in Hoppenrath et al. (2013), we consider here that $P$. faustiae and $P$. concavum are conspecific in 220 absence of significant morphological and genetic differences. As $P$. concavum was described earlier 221 (Fukuyo 1981), it has the priority over P. faustiae which we consider here as a junior synonym.

\section{- Prorocentrum cf. tropicale Faust}

224 Cells were broadly oval, with the maximum width behind the middle part. In the culture, they were $22535.8-39.8 \mu \mathrm{m}$ in legnth (mean $37.6 \mu \mathrm{m}$, s.d. $1.1 \mu \mathrm{m}, \mathrm{n}=20$ ) and 31.2-35.2 $\mu \mathrm{m}$ in width (mean 33.3 $226 \mu \mathrm{m}$, s.d. $1.2 \mu \mathrm{m}, \mathrm{n}=20$ ). The length to width ratio varied from 1.09 to 1.18 (mean 1.13 , s.d. $0.02, \mathrm{n}=$ 227 20). The periflagellar area was in a V-shaped depression of the right lateral plate and was composed of 228 nine platelets (1a, 1b, 2, 3, 4, 5, 6, 7 and 8) (Fig. 2c). The thecal surface was reticulate-foveate (Figs 229 2a, b) and the intercalary band horizontally striated (Fig. 2c).

230 Prorocentrum tropicale is a poorly known species described by Faust (1997) from Carrie Bow 231 Cay (Belize). Since its description, this species has never been reported in any another site, making no 232 further comparison possible. In Martinique Island, cells were collected on the sediment while the 
233 specimens studied by Faust (1997) were epiphytic on detritus or coral rubble. In our culture, cells

234 were smaller than the range given in the original description $(50-55 \mu \mathrm{m}$ in length and $40-45 \mu \mathrm{m}$ in 235 width, Faust 1997), but it might be a bias resulting from culture conditions and a growth rate that is 236 not comparable with field specimens. Except the size, most of the morphological features were in 237 agreement with the description, including the horizontally striated intercalary band. Unfortunately, the 238 pattern of the periflagellar area was not clearly illustrated with enough details by Faust (1997) and it 239 cannot be further compared. Although Faust (1997) mentioned 8 platelets, some may have been 240 overlooked. Because of these discrepancies and in absence of a reinvestigation of the type material, it 241 was not possible to confirm the identity of the specimens from Martinique Island. Provisionally, we 242 considered them as $P$. cf. tropicale as they were morphologically closely related to this species but 243 further analyses are necessary.

- Prorocentrum cf. foraminosum Faust (subclade A3)

246 Cells were oval oblong in shape (Figs $2 \mathrm{~g}-\mathrm{h}$ ), $43-49 \mu \mathrm{m}$ in length (mean $45.6 \mu \mathrm{m}$, s.d. $1.8 \mu \mathrm{m}, \mathrm{n}=12$ ) and 30-36 $\mu \mathrm{m}$ in width (mean $33.2 \mu \mathrm{m}$, s.d. $1.6 \mu \mathrm{m}, \mathrm{n}=12$ ). Length to width ratio varied from 1.31

248 to 1.53 (mean 1.37 , s.d. $0.06, \mathrm{n}=12$ ). The periflagellar area was in a small and narrow V-shaped 249 depression of the right lateral plate while the left thecal plate had a nearly flat edge (Figs $2 \mathrm{~g}-\mathrm{i})$. Nine platelets were identified (1a, 1b, 2, 3, 4, 5, 6, 7 and 8). Platelet 1a was large, almost triangular in shape and beared a large triangular flattened depression . Just below this platelet, a smaller rectangular platelet $1 \mathrm{~b}$ was present. Both of these platelets were protruding over the accessory pore and platelets located beneath, making this area difficult to study. Platelet 2 was rather small, with a narrow rectangular shape higher than wide. Platelet 3 was distinctive in being narrower towards the sagittal suture and widening on its side in contact with the flagellar pore (Fig. 3j). Platelet 4 was similar in size than platelet 1a, and had roughly the same shape, reversed, but its central depression was smaller. Platelet 5 had a J-shape and is in contact with the flagellar pore. Platelet 6 was small and rectangular, located below platelet 8. Platelet 7 was hardly visible in SEM because of the overlap of platelets 1a and $1 \mathrm{~b}$, but its end was seen in some specimens. Platelet 8 was small and separated the flagellar pore (which was partially visible below the platelets $1 \mathrm{a}$ and $1 \mathrm{~b}$ ) from the accessory pore. The thecal surface was smooth, and covered with scattered thecal pores, except in the centre. Thecal pores were 0.13-

$2620.15 \mu \mathrm{m}$ in diameter and were located in shallow depressions (diameter ca. $0.4 \mu \mathrm{m}$ ), which were more 
conspicuously visible when cells were in an oblique view. The number of pores on a lateral plate varied from 275 to 320, with an average of 296 (s.d. 16.0, $\mathrm{n}=8$ ). The intercalary band was smooth, narrow in young specimens or much wider in older ones (Figs $2 \mathrm{i}-\mathbf{j}$ ).

Morphologically, all the features observed on specimens from Martinique Island were in agreement with the original description of $P$. foraminosum from Hidden Lake, Twin Cays (Belize) (Faust 1993). In addition, we observed the presence of a central pyrenoid and found cells sometimes encased in mucus as mentioned by Faust (1993). Moreover, we found that the organization of the periflagellar area is remarkably similar (cf. Fig. 12 in Faust 1993) and we consider that it can ensure the species identification (Hoppenrath et al. 2013). Apart the original description, it was reported by Mohammad-Noor et al. (2007a) but the morphology was somewhat different from the type material and the identification cannot be ascertained as the ornamentation is a not a reliable feature. Indeed, a species with a typical foveate ornamentation and a similar size has been putatively identified as ' $P$. foraminosum' in the northern Atlantic and Sea of Japan (Hoppenrath et al. 2013; Kameneva et al. 2015; Selina 2017) but the sequences acquired for this temperate species are divergent from those obtained in the present study (Fig. 1). In the light of the new molecular data, it appears that the tropical specimens from Martinique Island fit well with $P$. foraminosum while those from the temperate area form a well separate clade (subclade A2) and likely correspond to another, yet undescribed species. Owing to the absence of DNA sequences from the original description and type locality, it is not yet possible to ascertain the identity of specimens from Martinique Island, although the morphology is very similar to $P$. foraminosum. In contrast, the morphology of specimens from the Atlantic and North Sea was not exactly similar and the species was misidentified since it differs more with the original description of $P$. foraminosum than the specimens studied herein. A detailed analysis and a description of this temperate species (subclade A2) is out of focus of the present paper and will be published in a separate study.

\section{Clade B - Prorocentrum lima complex and related species}

This large clade comprised sequences of $P$. lima and related species such as $P$. consutum, $P$. bimaculatum, P. lima (including several morphotypes), P. caipirignum, a species previously 
encompassed within the $P$. lima species complex, and $P$. hoffmannianum. Two sequences acquired in

293 the study were ascribed to P. lima and P. hoffmannianum on a morphological basis.

- Prorocentrum lima (Ehrenberg) F. Stein

Cells with two distinct morphotypes were found in Martinique. Broadly ovate to pyriform specimens (Figs 3a-b) were 31.1-34.6 $\mu \mathrm{m}$ in length (mean $32.6 \mu \mathrm{m}$, s.d. $1.5 \mu \mathrm{m}, \mathrm{n}=5$ ) and 28.4-31.3 $\mu \mathrm{m}$ in width (mean $29.6 \mu \mathrm{m}$, s.d. $1.3 \mu \mathrm{m}$ ), with a length to width ratio of 1.10-1.11. In contrast, oblong oval cells (Figs 3c-d) were 37.1-38.2 $\mu \mathrm{m}$ in length (mean $37.8 \mu \mathrm{m}$, s.d. $0.5 \mu \mathrm{m}, \mathrm{n}=5$ ) and 27.8-32.3 $\mu \mathrm{m}$ in width (mean $30.6 \mu \mathrm{m}$, s.d. $1.8 \mu \mathrm{m}, \mathrm{n}=5$ ), with a length to width ratio varying from 1.18 to 1.36. For both morphotypes, the periflagellar area consisted in eight platelets (Fig. 3e). The thecal surface was smooth without any ornamentation (Figs 3a-e). Thecal pores were present on the surface of lateral plates, and in a marginal ring but they were absent in the centre. In the pyriform morphotype, they were round to oval, $0.4-0.5 \mu \mathrm{m}$ in diameter, but in some specimens, marginal pores were more elongated (Fig. 3b). In the oblong-oval morphotype, the pores were more elongated to kidney-shaped and 0.6-0.8 $\mu \mathrm{m}$ long; the marginal pores were elongated and appeared as short lines (Figs 3c-d).

From the previous work by Zhang et al. (2015), the broadly-ovate to pyriform morphotype corresponds to 'morphotype 1' and the sequence is closely related to other sequences from various localities including Reunion Island, Malaysia, and tropical Australia. Unfortunately, despite efforts to obtain sequences for both morphotypes, a single sequence corresponding to morphotype 1 has been acquired in the study while the other morphotype can be compared only by its morphology. The broadly oblong specimens with kidney-shaped pores are morphologically very similar to those identified as $P$. lima 'morphotype 4' by Zhang et al. (2015) or more recently as $P$. cf. maculosum by

315 Luo et al. (2017). Nevertheless, we consider that this interpretation was mistaken since P. maculosum

316 is a typically foveate species (Faust 1993b) and it is very unlikely that all specimens of a foveate species are completely smooth, although ornamentation is variable with cell age (Hoppenrath et al.

318 2013). Interestingly, the sequences associated with the 'morphotype 4' of Zhang et al. (2015) and

319 those of $P$. cf. maculosum in Luo et al. (2017) are now genetically related to $P$. caipirignum, a recently 320 described species from Brazil, morphologically very close to P. lima (Nascimento et al. 2017). This 
321 species is completely smooth, like $P$. lima and $P$. cf. maculosum in Luo et al. (2017). The presence of

322 P. caipirignum in Martinique Island cannot be excluded since some specimens had this morphology,

323 but it should be confirmed with a molecular identification since morphology is not sufficient to

324 distinguish it from other morphotypes of $P$. lima. Owing to the great diversity of morphologies shown

325 in the present study, further research in Martinique Island should clarify the genetic diversity in this 326 group.

328 - Prorocentrum hoffmannianum Faust

329 Cells were broad oval in shape (Figs 3f-g), 46.8-52.5 $\mu$ m in length (mean $48.8 \mu \mathrm{m}$, s.d. $2.6 \mu \mathrm{m}, \mathrm{n}=5$ )

330 and 39.5-43.1 $\mu \mathrm{m}$ in width (mean $41.9 \mu \mathrm{m}$, s.d. $1.5 \mu \mathrm{m}, \mathrm{n}=5$ ). The length to width ratio varied from 3311.12 to $1.22(\mathrm{n}=5)$. The periflagellar area was V-shaped (Figs $3 \mathrm{~h}-\mathrm{i})$, composed of 8 platelets, but 332 platelet '7' was not visible and hidden by platelet 1 (Fig. 3i). The thecal surface was reticulate-foveate 333 with scattered thecal pores, except in the centre of lateral plates. A ring of marginal depressions 334 containing pores was conspicuously visible. The pores were elongated in shape. The intercalary band 335 was smooth, without striation (Fig. 3h).

Although this species is variable in morphology (Hoppenrath et al. 2013; Herrera-Sepúlveda et al. 2015), the specimens from Martinique Island are in agreement with the characteristic features given in the original description (Faust 1990a; Faust and Gulledge 2002). The molecular sequence obtained in this study also confirmed that specimens from Martinique Island were closely related to the strain CCMP683 which has been collected in the Caribbean Sea, off Knight Key (Florida) by J.

342 Bomber and unambiguously ascribed to $P$. hoffmannianum. The level of genetic variability in this 343 clade has been studied in details by Herrera-Sepúlveda et al. (2015) who also proposed that $P$. 344 belizeanum is a junior synonym of $P$. hoffmannianum, as morphological and molecular features to 345 distinguish these species are not strong enough. This species is known for the production of several toxic compounds (Faust and Gulledge 2002; Lassus et al. 2016). 
349 This clade comprised 7 sequences all acquired in the present study.

350 Cells were oval with more or less straight sides (Figs 4a-d), 31-37 $\mu \mathrm{m}$ in length (mean $33.9 \mu$ m, s.d. $3512.2 \mu \mathrm{m}, \mathrm{n}=6$ ) and 20-26 $\mu \mathrm{m}$ in width (mean $23.1 \mu \mathrm{m}$, s.d. $1.8 \mu \mathrm{m}, \mathrm{n}=6$ ). The length to width ratio 352 varied from 1.37 to 1.68 . The lateral plates were slightly asymmetric with the ventral side more 353 prominent than the dorsal, the anterior end appearing slightly oblique with respect of the longitudinal 354 axis of the cell (Figs 4c-d). The apical area of the left lateral plate was slightly concave (Fig. 4f). The 355 periflagellar area appeared rather flat area and not deeply excavated in the right plate (Figs 4c-d). It 356 was wide (Fig. 4c) and composed of 9 platelets (1a, 1b, 2, 3, 4, 5, 6, 7, 8) (Fig. 4g). The thecal surface 357 was smooth and perforated with pores excempt in the valve center. The intercalary band was striated 358 transversally (Fig. 4e). first description, $P$. norrisianum has been only putatively identified by Mohammad-Noor et al. (2007). However, the specimens from Malaysia were much smaller than in the original description, and the number of periflagellar platelets was apparently different. The presence of two sizes of thecal pores, as reported by Faust (1997) is a questionable feature since no illustration show this feature unambiguously. A careful re-examination of the Figs 1 and 2 in Faust (1997) showed that the 'small pores $(<0.05 \mu \mathrm{m})$ ' correspond better to small pits (depressions) rather than perforations in the theca. Furthermore, the Figs 3-4 revealed that the cells surface was covered by a granular layer that probably resulted from an artefact of preparation (coating) and it does not allow a careful observation of the surface.

The specimens collected in Martinique Island do not fit completely with the features of $P$. norrisianum and all specimens were larger than in the original description. A reinvestigation of this species from Belizean samples is absolutely necessary to confirm its morphological features and provide a reference sequence for subsequent identifications. The sequences clustered in two subclades

374 (Fig. 1) although we were not able to discriminate the specimens morphologically (Figs 4a-b), which

375 either indicate some genetic variations within the species or the existence of two cryptic species. However, specimens were rare and the low number of isolated cells did not allow further interpretations. It cannot be excluded that the species are pseudo-cryptic and that more detailed 
observations can reveal discriminating features. This remains to be checked in the future, using clonal cultures.

\section{Clade E - Prorocentrum glenanicum / P. panamense}

Three sequences from Martinique island clustered in this clade which encompasses species characterized by a 'linear' periflagellar area and an asymmetry (Hoppenrath et al. 2013). One sequence grouped with sequences of $P$. glenanicum and two sequences with $P$. panamense.

\section{- Prorocentrum glenanicum Chomérat et Nézan}

Cells were almost circular in shape (Figs 5a-b), 23.4-27.1 $\mu \mathrm{m}$ (mean $25.7 \mu \mathrm{m}$, s.d. $0.9 \mu \mathrm{m}, \mathrm{n}=15$ ) in length and 22.0-27.0 $\mu \mathrm{m}$ in width (mean $24.4 \mu \mathrm{m}$, s.d. $1.1 \mu \mathrm{m}, \mathrm{n}=15$ ). The length to width ratio varied from 0.99 to 1.12. The periflagellar area was almost flat and comprised 9 platelets $(1,2,3,4,5$, 6a, 6b, 7, 8) (Fig. 5c). Platelets 1 and 4 possessed several depressions. The thecal surface was smooth with pores in shallow depressions (foveate) distributed in a very distinctive pattern. A ring of marginal pores was present on both lateral plates (Figs 5a-b, d-e), but on the right plate, two areas of densely arranged pores were present in the subcentral part (Figs 5a, f) and in the posterior dorsal part (Figs 5a, d). The intercalary band was smooth and slightly transversally striated in older specimens (Fig. 5d-e).

Compared with the original description from the temperate area, no morphological difference was revealed in the specimens from Martinique Island (Chomérat et al. 2011). In addition, the LSU rDNA sequence acquired in this study is very similar to that obtained from the type locality (Glénan archipelago, South Brittany), indicating a very low genetic variation in this species. Although it was never abundant in the temperate samples, this small species was found in great abundance in some samples from Martinique Island. To date, it has not been reported in any other area than the Atlantic.

\section{- Prorocentrum panamense Grzebyk, Sako et Berland}

Cells were large, 39.8-46.1 $\mu \mathrm{m}$ in length (mean $42.4 \mu \mathrm{m}$, s.d. $2.6 \mu \mathrm{m}, \mathrm{n}=5$ ) and 38.2-42.0 $\mu \mathrm{m}$ in width (mean $40.1 \mu \mathrm{m}$, s.d. $1.7 \mu \mathrm{m}, \mathrm{n}=5$ ). They were asymmetrical, with a typical heart-shape. The 
periflagellar appeared flat and it was not excavated in the right lateral plate. It consisted in 9 platelets $(1,2,3,4,5,6 a, 6 b, 7,8)$ (Fig. 5i). The ornamentation was reticulate-foveate, with the presence of a large depression with sieve-plate on the posterior dorsal part (Figs $5 \mathrm{~g}, \mathrm{j}$ ).

From a morphological point of view, this species is very peculiar and morphologically easy to recognize. The type locality of this species was Contadora Island, on the Pacific side of Panama, which is just a little southern to Martinique Island. It has been found also in Arabian Gulf (Saburova, pers. comm.) and more recently in China (Luo et al. 2017). As shown by the sequences, and although specimens were isolated from distant areas (Martinique Island and China), the intraspecific level of genetic variation appears to be low in the LSU (Fig. 1).

\section{Clade F - Prorocentrum emarginatum/fukuyoi complex}

416 This clade grouped sequences of species characterized by an asymmetry of the anterior dorsal and ventral parts, and a deep, narrow $\mathrm{V}$-shaped periflagellar with a wing. The sequences clustered in two principal subclades: F1, corresponding to $P$. emarginatum complex, and F2 to $P$. fukuyoi complex 419 (Fig. 1).

subclade F1 - Prorocentrum emarginatum/sculptile complex

422 The subclade F1 was divided into a F1a branch comprising three sequences from GenBank identified 423 as Prorocentrum emarginatum and one ascribed to P. sculptile (NMN011) but no sequence from 424 Martinique Island while the clade F1b grouped 8 sequences, all from this study, that we identified morphologically as $P$. cf. sculptile.

$426-$ P. cf. sculptile Faust (Clade F1b)

427 Cells were oval (Figs 6a-f, 7a-e), 28.5-35.8 $\mu$ m in length (mean $33.4 \mu \mathrm{m}$, s.d. $1.7 \mu \mathrm{m}, \mathrm{n}=19$ ) and $428 \quad 27.7-32.8 \mu \mathrm{m}$ in width (mean $30.4 \mu \mathrm{m}$, s.d. $1.5 \mu \mathrm{m}, \mathrm{n}=19$ ). The length to width ratio varied from 4291.01 to 1.16 (mean 1.10). The periflagellar area was deep, narrow V-shaped and with a conspicuous 430 wing formed by platelet 1 . It was composed of 10 periflagellar platelets $(1,2,3,4,5,6 \mathrm{a}, 6 \mathrm{~b}, 7,8 \mathrm{a}, 8 \mathrm{~b})$ 431 (Figs 7h-k). Some platelets are difficult to observe such as platelet 7 which was located underneath the 432 wing formed by platelet 1 (Figs 7i-k). The division of platelet 8 was seen only when the cell was in a 
433 peculiar position but this feature has been observed in several specimens (Figs $7 \mathrm{j}-\mathrm{k}$ ). The thecal plates

434 were foveate, with depressions more or less visible depending on the thickness of the thecae (Figs 7a-

$435 \mathrm{~b}, \mathrm{~d}-\mathrm{e})$. On young specimens, the foveate ornamentation was visible only in the margin of lateral

436 plates, while the centre was smooth and devoid of depressions (Fig. 7c). Sequencing of single cells

437 possessing this peculiar feature (e.g. IFR13-108) revealed that they are genetically identical to

438 completely foveate specimens (e.g. IFR13-107 and IFR13-111, Figs 6a-f) (Fig. 1). The thecal pores

439 were arranged in radiating lines more conspicuously visible in LM or in specimens with a light foveate

440 ornamentation. The intercalary band was smooth and its size increased with cell age (Figs $7 \mathrm{f}-\mathrm{g}$ ). In

441 LM, some cells possessed a central structure resembling a pyrenoid (Fig. 5a) but other specimens

442 genetically identical lacked this feature (Fig. 5d).

The morphological features observed in specimens in the present study are in agreement with

444 the description of $P$. emarginatum but also with that of $P$. sculptile as some cells possessed a pyrenoid-

445 like structure as described by Faust (1994). Many confusions have occurred for species of the ' $P$.

446 emarginatum complex'. Back to the protologue in the original description of $P$. emarginatum from the

447 Ryukyu Island (Fukuyo 1981, p. 968), the author clearly stated that 'valve has spinule depressions

448 scattered all over, and in some specimens the depressions are so numerous that the valve seems to [be]

449 densely punctate'. Although he used only the light microscope, these minute depressions (foveate

450 ornamentation) can be clearly seen on the micrographs (Figs 11-12 in Fukuyo 1981) and the careful

451 reading indicated that he observed some variability in the ornamentation. Later, when she putatively

452 identified P. emarginatum from Belize, Faust (1990) described specimens with radiating lines of pores

453 and a completely smooth surface, which is clearly in contradiction with Fukuyo's original description

454 and likely correspond to a species in the 'P. fukuyoi complex'. This interpretation caused many

455 confusions in subsequent works and some authors (e.g. Mohammad-Noor et al. 2007a; Murray et al.

456 2007; Laza-Martínez et al. 2011) considered that a smooth ornamentation is a typical feature of $P$.

457 emarginatum, which is based on a mistaken interpretation. When Faust (1994) described P. sculptile

458 with a foveate thecal ornamentation in contrast with ' $P$. emarginatum', she added some confusion since

459 from a morphological point of view, these specimens fit well with the original description of $P$.

460 emarginatum sensu Fukuyo. She did not mention the radiating pore pattern probably because of the

461 strong foveate ornamentation of the theca, but this character is conspicuous in some original pictures

462 by M.A. Faust (e.g. \#281001; 281005) available in the Botany collection 2229-2000 from the

463 Smithsonian Institution (https://collections.nmnh.si.edu/search/botany/). Hence, P. sculptile possesses 
464 a similar pore pattern than P. emarginatum. As pointed out by Hoppenrath et al. (2013), the criteria 465 on which these species can be reliably distinguished are yet unclear. The size range given for $P$. 466 sculptile (32-37 $\mu \mathrm{m}$ long, 30-32 $\mu \mathrm{m}$ wide) is rather similar with the original description of $P$. 467 emarginatum (35-36 $\mu \mathrm{m}$ long, $32 \mu \mathrm{m}$ wide) and size can not be used to distinguish these two species. 468 A difference in the 'apical collar' has been reported between the two species, but the argument that the 469 wing is curved in P. scultpile and straight in P. emarginatum is not convincing as no detail was given by 470 Fukuyo (1981) making no comparison possible. Moreover, the variability of this feature in a 471 population has not been checked and the number of specimens shown in Faust (1994) is insufficient.

472 Another feature which may distinguish P. emarginatum from $P$. sculptile is the presence of a 473 conspicuous starch-ring pyrenoid in the latter which has not been reported in the former. However, this statement should be considered with care since Mohammad-Noor et al. (2007a) observed a pyrenoid in a Malaysian population of ' $P$. emarginatum' and pyrenoids are not always conspicuous in LM. In the present study, this feature was not clear and the fixed nature of the samples might bias our interpretation. Ultrastructural studies using transmission electron microscopy are necessary to check the presence and the type of pyrenoid in the cells (Mohammad-Noor et al. 2007b).

From a molecular point of view, only very few sequences have been ascribed to $P$. emarginatum in GenBank but none are from the type locality, which is a major problem to assess the identity of this species. Since all the sequences in the clade F1a are from Asia/Indian Ocean, we agree with Luo et al. (2017) in identifying them as P. cf. emarginatum since this species was described from the Japanese Pacific and because the morphology is compatible with the original description. In particular some cells were slightly foveate (cf. Fig. 3H in Luo et al. 2017), as reported by Fukuyo (1981). Furthermore, a single LSU rDNA sequence (NMN011, EF566749) has yet been ascribed to P. sculptile but it is very similar to P. emarginatum, as emphasized by Luo et al. (2017). In our opinion this sequence corresponds to the same species and specimens with or without a pyrenoid identified by Mohammad-Noor et al. (2007) were likely conspecific, as shown in our study. In contrast, the new sequences provided herein for specimens from the Eastern Caribbean are well divergent from $P$. cf. emarginatum and correspond to a genetically separate taxon. The morphology and geographic origin (Caribbean Sea) of the specimens from Martinique Island suggest that they are likely identical to $P$. sculptile but in absence of genetic reference, we can only provide a provisional identification. Owing to

493 the poor morphological differences to distinguish $P$. sculptile from P. emarginatum and a description 494 based on a mistaken interpretation of the latter, the existence of two separate taxa was in question 
495 (Hoppenrath et al. 2013). Our molecular data suggest that $P$. sculptile is a distinct, valid species as all

496 our specimens clustered in well supported clade distinct from $P$. cf. emarginatum. Nevertheless,

497 further analyses should assess the level of genetic variations within P. emarginatum and P. sculptile

498 from their type localities and various places in order to clarify the delimitation of these two

499 problematic species. Such molecular data are absolutely necessary to confirm that $P$. cf. sculptile from

500 Martinique Island corresponds to the same taxon than described in Belize by Faust (1994) or to

501 another cryptic, and yet undescribed species.

subclade F2 - P. fukuyoi complex

504

505

506

507

508

509

In the phylogenetic analysis, the 26 sequences comprised within the clade F2 clustered in five subclades statistically supported: F2a, F2b, F2c, F2d and F2e (Fig. 1). Among the 13 sequences from Martinique Island, 8 clustered in the subclade F2a and 5 grouped in subclade F2b (Fig. 1).

Morphologically, some differences were found among the specimens from these two subclades.

- P. cf. fukuyoi subclade F2a

Cells were oval-oblong in shape, conspicuously asymmetric with the dorsal side more bulging than the ventral side (Figs 6g-i, 8a-b). Cells were 37.0-39.6 $\mu$ m in length (mean $37.7 \mu \mathrm{m}$, s.d. $1.3 \mu \mathrm{m}, \mathrm{n}=6$ ) and 28.6-33.3 $\mu \mathrm{m}$ in width (mean $31.8 \mu \mathrm{m}$, s.d. $1.6 \mu \mathrm{m}, \mathrm{n}=6$ ). The length to width ratio varied from 1.15 to 1.26 (mean 1.20). The periflagellar area was deep and narrow, V-shaped and consisted in 10 platelets $(1,2,3,4,5,6 \mathrm{a}, 6 \mathrm{~b}, 7,8 \mathrm{a}$ and 8b) (Figs 8c-f). Platelet 1 beared a prominent rectangular wing on almost all its length. The subdivision of platelet 8 was difficult to see but appeared to be present on the margin of the accessory pore (Figs 8e-f). The thecal surface was not completely smooth but some very shallow depressions are present (faint foveate ornamentation). The depressions were $0.6-0.8 \mu \mathrm{m}$ in diameter. Thecal pores were arranged in radiating rows, with the centre of the lateral plates devoid of pores. Pores of two sizes were observed: large pores were $0.26 \mu \mathrm{m}$ in diameter, surrounded by a small rim and located in the faint depressions while the small pores were $0.15 \mu \mathrm{m}$ and not in depressions (Figs 8d-e). A ring of marginal small pores was present.

Morphologically, these specimens differ from the original description of $P$. fukuyoi, which is smooth (Murray et al., 2007). However, they are very similar to the strain Dn33EHU studied by Laza Martínez (2011). Although it was described as smooth, the illustrations of this strain show that the 
524 surface of thecal plates has some shallow depressions (cf. Fig. 41 in Laza Martínez et al. 2011), as 525 observed in this study.

528 Cells were oval oblong in shape (Figs $6 \mathrm{j}-1,8 \mathrm{~g}-\mathrm{h}$ ), slightly asymmetric, $29.9-37.5 \mu \mathrm{m}$ in length (mean $52934.7 \mu \mathrm{m}$, s.d. $3.4 \mu \mathrm{m}, \mathrm{n}=5$ ) and 23.2-31.2 $\mu \mathrm{m}$ in width (mean $27.8 \mu \mathrm{m}$, s.d. $3.5 \mu \mathrm{m}, \mathrm{n}=5$ ). The length to width ratio varied from 1.20 to 1.31 (mean 1.25). The periflagellar area was deep and narrow, V-shaped but due to the low number of specimens studied, the number of platelets has not been assessed. Platelet 1 formed a prominent wing (Fig. 8i). Thecal pores were arranged in radiating rows, with the centre of the lateral plates devoid of pores. specimens appear to be morphologically very similar to those observed by Faust (1990) both in shape and ornamentation, but they differ widely from $P$. emarginatum sensu Fukuyo.

As shown by the phylogenetic analysis, the clade F2 contains a considerable level of genetic variability (Fig. 1, Table 1). Although five subclades could be identified, the distinction of different morphoptypes or cryptic species is not yet clear. Murray et al. (2007) described $P$. fukuyoi using the strain SM19 as the type. In the same study, the authors analyzed morphologically the strains SM39 and SM35 and identified them as ' $P$. fukuyoi' and 'P. emarginatum', respectively. Morphologically, the strain SM35 was smooth (Murray et al. 2007) which did not fit with the original description of $P$. emarginatum, and it was probably misidentified. The strain SM39 (putatively P. fukuyoi) was not included in the phylogenetic analysis, and except the slight morphological difference in shape with the strain SM19 (type), they were regarded as conspecific. Murray et al. (2009) later showed that the sequence of strain SM39 was more divergent from SM19 than with SM35, which confused the definitions of $P$. fukuyoi and P. emarginatum. Laza-Martínez et al. (2011) found a similar topology in their phylogenetic analysis and were unable to identify the strains. They ascribed them to an unidentified complex 'Prorocentrum sp. emarginatum/fukuyoi group'. The sequences from Martinique Island clustered in the subclade F2b which encompasses other sequences from the Atlantic and Mediterranean, including the strains Dn33EHU and Dn34EHU studied by Laza-Martínez et al. 
sequenced. Interestingly, specimens from the clade F2a were slightly foveate and this morphological

554 feature could appear as a potentially useful character to distinguish among these ribotypes in

555 Martinique samples. Nevertheless, the strains observed by Laza-Martínez et al. (2011) had a smooth

556 (Dn34EHU) and lightly foveate ornamentation (Dn33EHU) and both clustered in the clade F2b,

557 proving that this feature is not reliable. Moreover, the genetic distance between the subclades F2a and

$558 \mathrm{~F} 2 \mathrm{~b}$ is around 0.030 , which is lower than between the other subclades (0.041-0.072, Table 1). This

559 value is in the same order of magnitude than the within-group variability for the subclades F2c, F2d

560 and F2e for which the divergence reaches 0.060. (Table 1). Therefore, this variability is yet difficult to

561 interpret and no relationship can be found with the geographical origin of the specimens. The

562 considerable genetic divergence existing among the different strains and field populations may be

563 related to the existence of cryptic species which are not yet understood. With the current knowledge,

564 it is not yet possible to clarify the situation within the clade F2. As emphasized by Hoppenrath et al.

565 (2013), an intensive re-investigation of strains of $P$. cf. fukuyoi, from different areas in the world,

566 including the type locality, with morphological and molecular methods is required to redefine the

567 species identity and to understand intra-specific variability of the different features.

\section{Clade G - Prorocentrum rhathymum and planktonic species}

570 Only one benthic species from Martinique Island was found in this clade comprising mostly

571 planktonic Prorocentrum species (Fig. 1).

572 - Prorocentrum rhathymum Loeblich, Sherley et Schmidt

573 Cells were oval to oblong, asymmetric, 28.0-35.0 $\mu \mathrm{m}$ in length (mean 31.9 $\mu \mathrm{m}$, s.d. $2.8 \mu \mathrm{m}, \mathrm{n}=5$ )

574 and 18.1-24.5 $\mu \mathrm{m}$ in width (mean $21.0 \mu \mathrm{m}$, s.d. $2.5 \mu \mathrm{m}, \mathrm{n}=5$ ). The length to width ratio ranged from

5751.43 to 1.56 (mean 1.52). The periflagellar area was wide V-shaped and comprised 9 platelets $(1,2,3$,

$5764,5,6 a, 6 b, 7,8)$. Platelet 1 had a conspicuous wing, visible also in the left lateral view and a smaller

577 wing was present on platelet 4 (Fig. 9b). The thecal surface was smooth with a characteristic pore

578 pattern. Large pores were arranged in one apical row of ca. 5-6 large pores and several posterior

579 radial rows in shallow thecal furrows (Figs 9a, b, d). They were located in round depressions. Smaller

580 pores were scattered on the surface of the lateral plates, but some groups of 4-5 small pores were

581 found on the posterior margin of the cell (Fig. 9c). The plate centre was devoid of pores. 
Morphologically, the specimens from Martinique Island were smaller than described by

Loeblich et al. (1979) but in agreement with other descriptions of this common species (Hoppenrath et al. 2013). In contrast with the specimens observed by Faust (1990a) in the western Caribbean, the cells found in Martinique Island were completely smooth and without ornamentation. Interestingly, the specimens observed in this study possessed clumps of small pores in the posterior margin of the theca which have not been described by Loeblich et al. (1979) but shown by Laza-Martínez et al. (2011). Such groups of small pores might be related to production of mucous threads for the fixation of cells, as observed in other dinoflagellates (e.g. Hoppenrath et al. 2004; Saburova and Chomérat 2014). The possible synonymy with $P$. mexicanum has been discussed several times (see Hoppenrath et al. 2013) and is out of focus of the present paper. For this reason we follow the taxonomic treatment by Hoppenrath et al. (2013). From a molecular point of view, all sequences ascribed either to $P$. rhathymum or $P$. mexicanum are very similar and the partial LSU rDNA cannot help in distinguishing these two species.

\section{Unsequenced morphospecies}

598 During the study, we identified a few specimens for which we could not obtain a sequence due to the rarity of cells and/or unsuccessful DNA amplifications. Based on morphological features only, they were ascribed to two different morphospecies: $P$. cf. maculosum and $P$. cf. ruetzlerianum.

\section{- Prorocentrum cf. maculosum Faust}

602 Cells were broadly ovate, $50.5-51.5 \mu \mathrm{m}$ in length and $48.2-48.4 \mu \mathrm{m}$ in width $(\mathrm{n}=2)$. The length to 603 width ratio was 1.04-1.07. The periflagellar area was located in a wide V-shaped area. All platelets 604 could not be observed and only 7 were seen $(1,2,3,4,5,6,7$ ?, 8) (Figs 10c-d). Platelet 1, 3 and 4 605 had depressions while platelet 2 was completely smooth, as for platelet 5, 6 and 8. The platelets 1, 2, 6063,5 and 6 developed small lists forming a continuous list around the accessory and flagellar pores 607 (Fig. 10d). The thecal surface was foveate, with small shallow round depressions. Thecal pores were 608 round to kidney-shaped (Figs 10a-b), scattered on the theca, with a conspicuous marginal ring of 609 evenly spaced pores (Fig. 10c) but the centre of lateral plates was devoid of pores. 
The delimitation of this species is problematic as it differs from P. lima only by its 'rugose'

612 (i.e. foveate) ornamentation, kidney-shaped pores, and the equal size of the flagellar and accessory

613 pores (Faust 1993b). Morphologically, it appears as intermediate between P. lima that is completely

614 smooth and P. hoffmannianum that is reticulate-foveate. Specimens from Martinique Island were

615 larger than the original description of P. maculosum (Faust 1993b) but closer in size to $P$.

616 hoffmannianum (Hoppenrath et al. 2013). The few specimens observed in the study possessed a

617 foveate ornamentation and had kidney-shaped thecal pores, which is in agreement with the original

618 description of $P$. maculosum. During our observations, the accessory pore was not entirely visible

619 because of the overlap by platelet 2 and it could not be measured. Hence this feature could not be

620 evaluated and used as a taxonomic feature. As noticed by Faust (1993b), the periflagellar of $P$. cf.

621 maculosum was remarkably similar with that of $P$. hoffmannianum, suggesting that this feature is not

622 taxonomically reliable to distinguish between these taxa. Without rDNA sequence, we cannot

623 ascertain that this morphospecies is genetically distinct from P. lima or P. hoffmannianum and further

624 studies should resolve this taxonomic issue. In Martinique Island, we cannot conclude whether the

625 specimens studied correspond to immature cells of $P$. hoffmannianum with an incomplete

626 ornamentation, or to a separate species. As discussed above, Luo et al. (2017) identified smooth

627 specimens as $P$. cf. maculosum in China but their morphology differs from the description, and there

628 are genetically closely related to P. caipirignum.

- Prorocentrum cf. ruetzlerianum Faust

631 During the course of our study, only five specimens of this morphospecies were found in the material.

632 For this reason, we observed only two specimens by SEM and 3 were used for unsuccessful DNA

633 amplifications. Cells were broadly oval, 29.0-30.3 $\mu \mathrm{m}$ in length and 24.9-25.8 in width $(\mathrm{n}=2)$. The

634 length to width ratio was ca. 1.17. The periflagellar area was wide V-shaped (Fig. 10e), composed of

6357 platelets visible $(1,2,3,4,5,6,8)$. The thecal surface was reticulate-foveate (Figs 10e-g), except on

636 the margin of lateral plates and on the intercalary band where elongated depressions formed a

637 conspicuous striated pattern (Figs 10f-g). Thecal pores were scattered on the surface but the centre of

638 lateral plates was devoid of pores (Fig. 10e).

Morphologically, P. ruetzlerianum is a peculiar species characterized by a strong reticulate-

640 foveate ornamentation formed by deep, pentagonal areolae and a typical striated pattern on the margin 
641 of lateral plates and intercalary band, which is unique in the genus (Faust 1990a; Faust et al. 1999).

642 The specimens observed in this study possessed these features, but they were probably younger than

643 those observed by Faust (1990a) because the plates had shallower depressions, and the striated

644 intercalary band was not as wide (cf. Figs 21-24 in Faust 1990a). We did not observe a thecal pore in

645 all the areolae, which contrasts with the description (Faust 1990a), but this fact has already been

646 pointed out by Hoppenrath et al. (2013). Interestingly, the periflagellar area of the specimens studied

647 herein was very similar to that illustrated in the original description of P. ruetzlerianum (cf. Fig. 24 in

648 Faust 1990a). In particular, the small and almost square platelet 2, the wide rectangular platelet 3 and

649 the small elongated platelet 6 appear nearly identical. Only the shape of platelet 4 was somewhat

650 different and it appeared to be smaller in the original description (Faust 1990a). The apparent absence

651 of platelet 7 has already been mentioned by Hoppenrath et al. (2013), but unfortunately, the limited

652 number of specimens available did not allow further detailed observations of this area. The rarity of

653 this species has also been mentioned by Faust and Gulledge (2002). The morphological features argue

654 in favour of the identification of P. ruetzlerianum in Martinique Island, but further molecular studies

655 are necessary to confirm this in the future. This would be important since Faust and Gulledge (2002)

656 reported that this species produce toxins, but without giving the exact toxin profile. An extended study

657 of this poorly known species is therefore necessary.

\section{Conclusions}

660 The present study revealed a high diversity of benthic species of Prorocentrum at Anse Dufour,

661 Martinique Island. Thanks to the sequencing of the LSU rDNA, 11 species were recognized, while 2

662 other morphospecies were identified on a morphological basis only. Hence putatively 13 species are

663 present in the same site, including 5 potentially toxic species: P. concavum, P. lima, $P$.

664 hoffmannianum, $P$. cf. maculosum and P. cf. ruetzlerianum. Some of the species identified in the

665 study were not previously known from the Caribbean such as $P$. cf. glenanicum described from

666 temperate Atlantic. Interestingly, many species were also observed by Faust (e.g. Faust 1996, 2000) in

667 Belizean samples from the western Caribbean, and although the substrates sampled were different,

668 very similar assemblages were found. For instance, among the species found in Martinique Island, we

669 putatively identified the poorly known $P$. cf. tropicale and $P$. cf. ruetzlerianum which have not been 
reported in any study since their discovery. Some morphological features such as cell sizes were not identical with the original descriptions, so further investigations are necessary to confirm the identify of these taxa. The absence of reference sequences from Belizean coral reefs and mangrove habitats that constitute the type locality of several species, prevents genetic comparisons and their unambiguous identification. This issue occurs for several other species described by Faust in Twin Cays, like $P$. cf. foraminosum, $P$. cf. norrisianum or $P$. cf. sculptile for which the identifications only rely on morphological features and hence remain uncertain.

The molecular phylogenetic analysis realized in the study revealed that the topology of major clades is in agreement with previous published phylogenies of the genus (e.g. Hoppenrath et al. 2013). The acquisition of new sequences revealed one new clade, the clade $\mathrm{D}$ that encompasses $P$. cf. norrissianum, and three subclades that were previously unknown, such as the subclade A3 corresponding to $P$. cf. foraminosum and the subclades F1b and F2a corresponding, respectively, to $P$. cf. sculptile and a new ribotype of $P$. cf. fukuyoi. Interestingly, our phylogentic analysis placed $P$. cf. tropicale in the clade A of species related with P. concavum although we previously considered it as a putative member of the $P$. hoffmannianum complex (Hoppenrath et al. 2013). The major clades seem to be well supported by morphological differences of the periflagellar area of the taxa. All the species in the clade A appear to possess an excavated periflagellar area comprising 9 platelets with a similar pattern (split 1a/1b), although this is not very clear in P. leve (Mertens et al. 2017). This contrasts with the species in clade B related to ' $P$. lima' that mostly possess 8 platelets, or 6 as shown in $P$. caipirignum (Nascimento et al. 2017). The molecular phylogeny suggests that the number of periflagellar platelets might reflect a character evolution between the clades A and B. Comparatively, we found also 9 platelets in the clades D (P. cf. norrissianum) and E (P. glenanicum/P. panamense)

692 but their periflagellar area is only slightly excavated in the right lateral plate or almost 'flat', 693 respectively. We found 10 platelets arranged in a typical pattern for the specimens from the clade $\mathrm{F}$ 694 (P. emarginatum/P. fukuyoi complex) from Martinique Island. Based on the observations by Luo et al. 695 (2017), 9 platelets have been found in the strain X2P3 of P. cf. emarginatum, but it cannot be excluded that the subdivision of platelet 8 was obscured by the prominent wings. Finally, $P$. rhathymum (clade $\mathrm{G}$ ) possesses 9 platelets but with a very conspicuous and typical wing on platelet 1 and a short wing or list on the platelet 4 , which is also typical of many planktonic species. 
Our study also revealed a higher diversity than previously known in the clade F of $P$. emarginatum/P. fukuyoi complex. Thanks to the technique used specifically for taxa in this group, we were able to study the thecal plates of the single cells sequenced using SEM and associate the phenotypes with the genotypes, even in absence of cultures. For instance, the morphological features of specimens from the new clade F1b lead us to identify $P$. cf. sculptile since the characters and the geographical origin in the Caribbean were in agreement with the description of this species. As previously shown, the delimitation of $P$. cf. fukuyoi is unclear and the existence of two ribotypes in the samples studied confuses even more the taxonomy of this species. As shown by the diverse origins of the sequences ascribed to $P$. fukuyoi complex, this taxon seriously needs a reinvestigation to clarify the species boundaries and eventually identify new, cryptic species.

Although the morphology of the genus Prorocentrum appears to be simple because of its peculiar morphology among dinoflagellates, our study confirmed that species identification is complex for some taxa, even with addition of molecular data. As shown by our study, a combination of morphological and genetic features is absolutely necessary to better characterize the taxa. For some species, acquiring sequences from type localities appears as an utmost priority since the lack of molecular data prevents unambiguous identifications. In case of morphologically closely related taxa, genetic information is critical in order to permit descriptions of new species with no risk of redescriptions of already existing taxa. Hence, as recently emphasized by Hoppenrath (2017), there is

717 a serious need of further works on this genus in order to clarify the species delimitations which are 718 still not clear for several taxa.

\section{Acknowledgements}

720 We thank Maurice Loir for his invaluable help and long-term collaboration, Maria A. Faust for her 721 long-time encouragements and constant kindness, and Nicolas Gayet for critical point drying of the 722 samples and support with SEM. This research received no specific grant from any funding agency, 723 commercial or not-for-profit sector. 


\section{REFERENCES}

725 Besada EG, Loeblich LA, Loeblich AR III (1982) Observations on tropical, benthic dinoflagellates from ciguatera-endemic areas: Coolia, Gambierdiscus and Ostreopsis. Bull Mar Sci 32:723735 .

Boisnoir A, Pascal P-Y, Cordonnier S, Lemée R (2018) Depth distribution of benthic dinoflagellates in the Caribbean Sea. J Sea Res 135:74-83. doi: 10.1016/j.seares.2018.02.001

Bouaïcha N, Chézeau A, Turquet J, Quod J-P, Puiseux-Dao S (2001) Morphological and toxicological variability of Prorocentrum lima clones isolated from four locations in the south-west Indian Ocean. Toxicon 39:1195-1202.

Chomérat N, Bilien G (2014) Madanidinium loirii gen. et sp. nov. (Dinophyceae), a new marine benthic dinoflagellate from Martinique Island, Eastern Caribbean. Eur J Phycol 49:165-178.

Chomérat N, Couté A (2008) Protoperidinium bolmonense sp. nov. (Peridiniales, Dinophyceae), a small dinoflagellate from a brackish hypereutrophic lagoon (South of France). Phycologia 47:392-403.

Chomérat N, Saburova M, Bilien G, al-Yamani FY (2012) Prorocentrum bimaculatum sp. nov. (Dinophyceae, Prorocentrales), a new benthic dinoflagellate species from Kuwait (Arabian Gulf). J Phycol 48:211-221.

Chomérat N, Zentz F, Boulben S, Bilien G, van Wormhoudt A, Nézan E (2011) Prorocentrum glenanicum sp. nov. and P. pseudopanamense sp. nov. (Prorocentrales, Dinophyceae), two new benthic dinoflagellate species from South Brittany (northwestern France). Phycologia 50:202214.

Faust MA (1990a) Morphologic details of six benthic species of Prorocentrum (Pyrrophyta) from a mangrove island, Twin Cays, Belize, including two new species. J Phycol 26:548-558.

Faust MA (1990b) Cysts of Prorocentrum marinum (Dinophyceae) in floating detritus at Twin Cays, Belize mangrove habitats. In: Granéli E, Sundstrom B, Edler L, Anderson DM (eds) Toxic marine phytoplankton. Elsevier Science Publishing, New-York, pp 138-143 
750 Faust MA (1991) Morphology of ciguatera-causing Prorocentrum lima (Pyrrophyta) from widely differing sites. J Phycol 27:642-648.

752 Faust MA (1993a) Prorocentrum belizeanum, Prorocentrum elegans, and Prorocentrum caribbaeum, three new benthic species (Dinophyceae), from a mangrove island, Twin Cays, Belize. J Phycol 29:100-107.

Faust MA (1993b) Three new benthic species of Prorocentrum (Dinophyceae) from Twin Cays, Belize: P. maculosum sp. nov., P. foraminosum sp. nov. and P. formosum sp. nov. Phycologia 32:410-418.

Faust MA (1994) Three new benthic species of Prorocentrum (Dinophyceae) from Carrie Bow Cay, Belize: P. sabulosum sp. nov., P. sculptile sp. nov. and P. arenarium sp. nov. J Phycol 30:755763.

Faust MA (1996) Dinoflagellates in a mangrove ecosystem, Twin Cays, Belize. Nova Hedwig 112:447-460.

Faust MA (1995) Observation of sand-dwelling toxic dinoflagellates (Dinophyceae) from widely differing sites, including two new species. J Phycol 31:996-1003.

Faust MA (1999) Three new Ostreopsis species (Dinophyceae): O. marinus sp. nov., O. belizeanus sp. nov., and $O$. caribbeanus sp. nov. Phycologia 38:92-99.

Faust MA (2000) Dinoflagellate associations in a coral reef-mangrove ecosystem: Pelican and associated Cays, Belize. Atoll Res Bull 473:133-149.

Faust MA (2009) Ciguatera-causing dinoflagellates in a coral-reef-mangrove ecosystem, Belize. Atoll Res Bull 569:1-30. doi: 10.5479/si.00775630.569.1

773 Faust MA, Gulledge RA (2002) Identifying harmful marine dinoflagellates. Smithson Inst Contrib U S Natl Herb 42:1-144. 
775 Faust MA, Larsen J, Moestrup Ø (1999) Leaflet No. 184 - Potentially Toxic Phytoplankton. 3. Genus Prorocentrum. In: Lindley JA (ed) ICES Identification Leaflets for Plankton. International Council for the Exploration of the Sea, Copenhagen, pp 1-24

Faust MA, Morton SL (1995) Morphology and ecology of the marine dinoflagellate Ostreopsis labens sp. nov. (Dinophyceae). J Phycol 31:456-463.

Faust MA, Vandersea MW, Kibler SR, Tester PA, Litaker RW (2008) Prorocentrum levis, a new benthic species (Dinophyceae) from a mangrove island, Twin Cays, Belize. J Phycol 44:232_ 240.

Guindon S, Dufayard J-F, Lefort V, Anisimova M, Hordijk W, Gascuel O (2010) New algorithms and methods to estimate Maximum-Likelihood phylogenies: assessing the performance of PhyML 3.0. Syst Biol 59:307-21.

Guiry MD, Guiry GM (2018) AlgaeBase. World-wide electronic publication. http://www.algaebase.org. Accessed 28 Mar 2018

Herrera-Sepúlveda A, Medlin LK, Murugan G, Sierra-Beltrán AP, Cruz-Villacorta AA, HernándezSaavedra NY, Müller K (2015) Are Prorocentrum hoffmannianum and Prorocentrum belizeanum (Dinophyceae, Prorocentrales), the same species? An integration of morphological and molecular data. J Phycol 51:173-188. doi: 10.1111/jpy.12265

Hoppenrath M (2017) Dinoflagellate taxonomy — a review and proposal of a revised classification. Mar Biodivers 47:381-403. doi: 10.1007/s12526-016-0471-8

\section{Hoppenrath M, Chomérat N, Horiguchi T, Schweikert M, Nagahama Y, Murray S (2013) Taxonomy} and phylogeny of the benthic Prorocentrum species (Dinophyceae) - a proposal and review. Harmful Algae 27:1-28.

Hoppenrath M, Saldarriaga JF, Schweikert M, Elbrächter M, Taylor FJR (2004) Description of Thecadinium mucosum sp. nov. (Dinophyceae), a new sand-dwelling marine dinoflagellate, and an emended description of Thecadinium inclinatum Balech. J Phycol 40:946-961. 
Kameneva PA, Efimova KV, Rybin VG, Orlova TY (2015) Detection of Dinophysistoxin-1 in clonal culture of marine dinoflagellate Prorocentrum foraminosum (Faust M.A., 1993) from the Sea of Japan. Toxins Basel 7:3947-59. doi: 10.3390/toxins7103947

Katoh K, Standley DM (2013) MAFFT multiple sequence alignment software version 7: improvements in performance and usability. Mol Biol Evol 30:772-80. doi: 10.1093/molbev/mst010

Keane TM, Creevey CJ, Pentony MM, Naughton TJ, McInerney JO (2006) Assessment of methods for amino acid matrix selection and their use on empirical data shows that ad hoc assumptions for choice of matrix are not justified.

Keller MD, Selvin RC, Claus W, Guillard RRL (1987) Media for the culture of oceanic ultraphytoplankton. J Phycol 23:633-638.

Kimura M (1980) A simple method for estimating evolutionary rates of base substitutions through comparative studies of nucleotide sequences. J Mol Evol 16:111-120.

Lassus P, Chomérat N, Hess P, Nézan E (2016) Toxic and harmful microalgae of the world ocean. UNESCO, Denmark

Laza-Martínez A, Orive E, Irati M (2011) Morphological and genetic characterization of benthic dinoflagellates of the genera Coolia, Ostreopsis and Prorocentrum from south-eastern Bay of Biscay. Eur J Phycol 46:45-65.

Litaker RW, Vandersea MW, Faust MA, Kibler SR, Nau AW, Holland WC, Chinain M, Holmes MJ, Tester PA (2010) Global distribution of ciguatera causing dinoflagellates in the genus Gambierdiscus. Toxicon 56:711-30. doi: 10.1016/j.toxicon.2010.05.017

Loeblich AR, Sherley JL, Schmidt RJ (1979) The correct position of flagellar insertion in Prorocentrum and description of Prorocentrum rhathymum sp. nov. (Pyrrhophyta). J Plankton Res 1:113-120. doi: 10.1093/plankt/1.2.113 
Luo Z, Zhang H, Krock B, Lu S, Yang W, Gu H (2017) Morphology, molecular phylogeny and okadaic acid production of epibenthic Prorocentrum (Dinophyceae) species from the northern South China Sea. Algal Res 22:14-30. doi: 10.1016/j.algal.2016.11.020

Mertens KN, Gu H, Pospelova V, Chomérat N, Nézan E, Gurdebeke P, Bogus K, Vrielinck H, Rumèbe M, Méteigner C (2017) First recod of resting cysts of the benthic dinoflagellate Prorocentrum leve in a natural reservoir in Gujan-Mestras, Gironde, France. J Phycol 53:1193-1205. doi: 10.1111/jpy.12582

Mohammad-Noor N, Daugbjerg N, Moestrup Ø, Anton A (2007a) Marine epibenthic dinoflagellates from Malaysia - a study of live cultures and preserved samples based on light and scanning electron microscopy. Nord J Bot 24:629-690.

Mohammad-Noor N, Moestrup Ø, Daugbjerg N (2007b) Light, electron microscopy and DNA sequences of the dinoflagellate Prorocentrum concavum (syn. P. arabianum) with special emphasis on the periflagellar area. Phycologia 46:549-564.

Murray S, Nagahama Y, Fukuyo Y (2007) Phylogenetic study of benthic, spine-bearing prorocentroids, including Prorocentrum fukuyoi sp. nov. Phycol Res 55:91-102.

Nagahama Y, Murray S, Tomaru A, Fukuyo Y (2011) Species boundaries in the toxic dinoflagellate Prorocentrum lima (Dinophyceae, Prorocentrales), based on morphological and phylogenetic characters. J Phycol 47:178-189.

Nascimento SM, Mendes MCQ, Menezes M, Rodríguez F, Alves-de-Souza C, Branco S, Riobó P, Franco J, Nunes JMC, Huk M, Morris S, Fraga S (2017) Morphology and phylogeny of Prorocentrum caipirignum sp. nov. (Dinophyceae), a new tropical toxic benthic dinoflagellate. Harmful Algae 70:73-89. doi: 10.1016/j.hal.2017.11.001

Olsen DA, Nellis DW, Wood RS (1984) Ciguatera in the Eastern Caribbean. Mar Fish Rev 46:13-18.

Pottier I, Vernoux J-P, Lewis RJ (2001) Ciguatera fish poisoning in the Caribbean islands and Western Atlantic. Rev Environ Contam Toxicol 168:99-141.

Rasband WS (1997) ImageJ. National Institutes of Health, Bethesda, Maryland 
850 Ronquist F, Huelsenbeck JP (2003) MrBayes 3: Bayesian phylogenetic inference under mixed models. Bioinformatics 19:1572-1574.

852 Rosine J, J.L. C, Cardoso T, Quénel P (2008) La ciguatéra dans les Antilles Françaises.

853 Saburova M, Chomérat N (2014) Ailadinium reticulatum gen. et sp. nov. (Dinophyceae), a new 854 thecate, marine, sand-dwelling dinoflagellate from the northern Red Sea. J Phycol 50:1120855 1136.

Selina MS (2017) The morphology and seasonal dynamics of the potentially toxic microalga Prorocentrum foraminosum Faust 1993 (Dinophyta) in Peter the Great Bay, the Sea of Japan. Russ J Mar Biol 43:196-201. doi: 10.1134/S1063074017030099

Tamura K, Peterson D, Peterson N, Stecher G, Nei M, Kumar S (2011) MEGA5: Molecular Evolutionary Genetics Analysis using Maximum Likelihood, evolutionary distance, and Maximum Parsimony methods. Mol Biol Evol 28:2731-2739.

Taylor FJR (1985) The distribution of the dinoflagellate Gambierdiscus toxicus in the eastern Caribbean. In: Gabrié C, Salvat B (eds). MNHN-EPHE, pp 423-428

864 Tester PA, Feldman RL, Nau AW, Kibler SR, Litaker RW (2010) Ciguatera fish poisoning and sea surface temperatures in the Caribbean Sea and the West Indies. Toxicon 56:698-710. doi: 10.1016/j.toxicon.2010.02.026

Vernoux J-P (1988) La ciguatera dans l'île de Saint-Barthélémy : aspects épidémiologiques, toxicologiques et préventifs. Oceanol Acta 11:37-46. (Dinophyceae) from Hainan Island, South China Sea: morphological and molecular characterization. Phycologia 54:503-516. doi: 10.2216/15-8.1 
872 Table 1 Mean genetic distances (Kimura 2-parameter) within and net-between subclades of the $P$. cf. 873 fukuyoi complex (clade F2), based on the alignment of 26 sequences and 514 characters used 874 in the phylogenetic analysis

\begin{tabular}{lccccc}
\hline Subclades (groups) & $\begin{array}{c}\text { F2a } \\
\text { (8 sequences) }\end{array}$ & $\begin{array}{c}\text { F2b } \\
\text { (9 sequences) }\end{array}$ & $\begin{array}{c}\text { F2c } \\
\text { (3 sequences) }\end{array}$ & $\begin{array}{c}\text { F2d } \\
\text { (4 sequences) }\end{array}$ & $\begin{array}{c}\text { F2e } \\
\text { (2 sequences) }\end{array}$ \\
\hline Within groups & 0.000 & 0.007 & 0.024 & 0.026 & 0.060 \\
\hline Net between-groups & & & & & - \\
F2a & - & - & - & - & - \\
F2b & 0.030 & - & - & - & - \\
F2c & 0.072 & 0.045 & - & - & - \\
F2d & 0.062 & 0.041 & 0.051 & 0.044 & - \\
F2e & 0.070 & 0.047 & 0.057 & & - \\
\hline
\end{tabular}


Figure legends:

877 Fig. 1 Phylogenetic tree of Prorocentrum sequences rooted on Peridiniella spp., inferred from a LSU 878 rDNA matrix (135 sequences, 643 sites). The tree topology $(-\ln L=8260.79059)$ was obtained from 879 ML analysis. Symbols indicate branch support (bootstraps in ML/posterior probabilities in BI): thick 880 branch lines indicate a full support (100/1.00), filled triangles a strong support 90-99/0.95-0.99 and 881 filled circles a moderate support 80-89/0.80-0.94). Lower support values are not indicated. Sequences 882 obtained in the present study are highlighted in bold face and with a grey background

883 Fig. 2 Scanning electron micrographs of species in the clade A. a-c $P$. cf. tropicale: a right lateral view, b left lateral view, c detail of the periflagellar area; d-f P. concavum: $\mathbf{d}$ right lateral view, e left lateral view, $\mathbf{f}$ detail of the periflagellar area; $\mathbf{g}-\mathbf{m}$ P. cf. foraminosum: $\mathbf{g}$ right lateral view, $\mathbf{h}$ left lateral view, $\mathbf{i}$ apical view, $\mathbf{j}$ antapical view, $\mathbf{k}$ oblique view of the dorsal side, $\mathbf{l}$ detail of the foveate surface and thecal pores, $\mathbf{m}$ detail of the periflagellar area. Scale bars $10 \mu \mathrm{m}$ in a-b, d-e, g-h; $5 \mu \mathrm{m}$ in $\mathrm{i}-\mathrm{k} ; 2 \mu \mathrm{m}$ in $\mathrm{c}, \mathrm{f}, \mathrm{m}$ and $1 \mu \mathrm{m}$ in 1

Fig. 3 Scanning electron micrographs of species in the clade B. a-e P. lima: a-b broadly ovatepiriform morphotype, $\mathbf{b}-\mathbf{c}$ oblong-oval morphotype, e detail of the periflagellar area; $\mathbf{f}-\mathbf{i} P$. hoffmannianum: $\mathbf{f}$ right lateral view, $\mathbf{g}$ left lateral view, $\mathbf{h}$ apical view showing intercalary band, $\mathbf{i}$ detail of the periflagellar area. Scale bars $10 \mu \mathrm{m}$ in a-d, $\mathrm{f}-\mathrm{h} ; 2 \mu \mathrm{m}$ in e, i

893 Fig. 4 Light and scanning electron micrographs of $P$. cf. norrisianum (clade D). a-b LM micrographs of two sequenced specimens: a IFR15-204, b IFR15-205; c-g SEM micrographs: c right lateral view, $\mathbf{d}$ left lateral view, e apical view showing intercalary band, $\mathbf{f}$ detail of the apical area of the left lateral plate, $\mathbf{g}$ detail of the periflagellar area. Scale bars $10 \mu \mathrm{m}$ in a-e and $2 \mu \mathrm{m}$ in $\mathrm{f}-\mathrm{g}$

897 Fig. 5 Scanning electron micrographs of species in the clade E. a-f $P$. glenanicum: a right lateral 898 view, b left lateral view, $\mathbf{c}$ detail of the periflagellar area, $\mathbf{d}$ dorsal view of a specimen with a thin 899 intercalary band, $\mathbf{e}$ antapical view of a specimen with a large intercalary band, $\mathbf{f}$ detail of the central 900 area with pores; $\mathbf{g}-\mathbf{j}$ P. panamense: $\mathbf{g}$ right lateral view, $\mathbf{h}$ left lateral view, $\mathbf{i}$ detail of the periflagellar 901 area, $\mathbf{j}$ detail of the depression with a sieve-like bottom. Scale bars $5 \mu \mathrm{m}$ in a-b, d-e, $\mathrm{g}-\mathrm{h} ; 2 \mu \mathrm{m}$ in c, $902 \mathrm{f}, \mathrm{i}$ and $500 \mathrm{~nm}$ in $\mathrm{j}$

903 Fig. 6 Light (phase contrast) and scanning electron micrographs of single-cells sequenced in the clade 904 F. a-c LM micrographs of the specimen IFR13-107, d-e LM micrographs of the specimen IFR13- 
905 111, f SEM micrograph of the left lateral plate of specimen IFR13-111, $\mathbf{g}-\mathbf{h}$ LM micrographs of the 906 specimen IFR13-122, i SEM micrograph of the left lateral plate of specimen IFR13-122, j-k LM 907 micrographs of the specimen IFR13-113, I SEM micrograph of the left lateral plate of specimen 908 IFR13-113. All scale bars $10 \mu \mathrm{m}$

909 Fig. 7 Scanning electron micrographs of $P$. cf. sculptile (clade F1b). a right lateral view of cell with 910 strong foveate ornamentation, $\mathbf{b}$ right lateral view of cell with light foveate ornamentation, $\mathbf{c}$ right 911 lateral view of cell with a marginal foveate ornamentation and smooth centre, $\mathbf{d}$ left lateral view of cell 912 with strong foveate ornamentation, $\mathbf{e}$ left lateral view of cell with light foveate ornamentation, $\mathbf{f}$ apical 913 view, $\mathbf{g}$ antapical view, $\mathbf{h}-\mathbf{k}$ different views of the periflagellar area. The asterisk indicates the platelet 914 8a. Scale bars $10 \mu \mathrm{m}$ in a-g; $2 \mu \mathrm{m}$ in $\mathrm{h}$ and $1 \mu \mathrm{m}$ in $\mathrm{i}-\mathrm{k}$

915 Fig. 8 Scanning electron micrographs of $P$. cf. fukuyoi (clade F2). a-f foveate specimens of the 916 subclade F2a: a right lateral view, b left lateral view, c-f different views of the periflagellar area; $\mathbf{g}-\mathbf{i}$ 917 smooth specimens of the subclade F2b: $\mathbf{g}$ right lateral view, $\mathbf{h}$ left lateral view, $\mathbf{i}$ detail of the 918 periflagellar area. The asterisk indicates the platelet $8 \mathrm{a}$. Scale bars $10 \mu \mathrm{m}$ in $\mathrm{a}-\mathrm{b}, \mathrm{g}-\mathrm{h}$ and $1 \mu \mathrm{m}$ in $\mathrm{c}-\mathrm{f}$, 919 i

920 Fig. 9 Scanning electron micrographs of P. rhathymum (clade G). a right lateral view, b left lateral 921 view, c detail of antapical area showing the groups of small pores and large pores, $\mathbf{d}$ detail of the 922 periflagellar area. Scale bars $5 \mu \mathrm{m}$ in $\mathrm{a}-\mathrm{b}$ and $2 \mu \mathrm{m}$ in $\mathrm{c}$ and $\mathrm{d}$

923 Fig. 10 Scanning electron micrographs of unsequenced morphospecies. a-d $P$. cf. maculosum: a right 924 lateral view, b left lateral view, c apical view, $\mathbf{d}$ detail of the periflagellar area; $\mathbf{e}-\mathbf{g} P$. cf.

925 ruetzlerianum: e right lateral view, $\mathbf{f}$ apical view, $\mathbf{g}$ detail of the periflagellar area. Scale bars $10 \mu \mathrm{m}$ in $926 \mathrm{a}-\mathrm{c}, \mathrm{e} ; 5 \mu \mathrm{m}$ in $\mathrm{f}$ and $2 \mu \mathrm{m}$ in $\mathrm{g}$ 